\title{
A empresa jornalística como ator político: Um estudo quanti-qualitativo sobre o impeachment de Dilma Rousseff nos editoriais de Folha e Estadão
}

\section{The journalism as a political actor: A quantitative-qualitative study on the Dilma Rousseff's impeachment in the editorials of Folha and Estadão}

\author{
Francisco Paulo Jamil Marques*, Camila Mont'Alverne**, Isabele Batista Mitozo***
}

*Universidade Federal do Paraná, Brasil

**Universidade Federal do Paraná, Brasil

***Universidade Federal do Paraná, Brasil

Resumo

\begin{abstract}
$\mathrm{O}$ artigo examina como Folha de S. Paulo e O Estado de S. Paulo se posicionaram politicamente em seus editoriais acerca do impeachment de Dilma Rousseff. O estudo comparativo abrange as dimensões quantitativa e qualitativa de 507 editoriais ( $F S P=156$; OESP=351) publicados entre 2015 e 2016 que mencionam "impeachment" ou "impedimento", analisados por meio de Análise de Conteúdo. Propõem-se três hipóteses: Os editoriais de FSP e OESP: H1) Constroem, de forma sincronizada com o desenvolvimento do processo de impeachment nas esferas institucionais, a ideia de legitimidade do afastamento de Dilma; H2) Apresentam pontos de vista semelhantes em relação ao impeachment; H3) Ancoram a legitimidade do afastamento de Dilma, essencialmente, em argumentos jurídicos. Os resultados apontam que: os editoriais pautam o impeachment antes mesmo de a ação se iniciar institucionalmente; ambos se preocupam em validar o afastamento, mas mobilizam argumentos distintos; OESP defende o impeachment como saída mais adequada, enquanto FSP prefere a renúncia de Dilma e Temer, seguida de novas eleições.
\end{abstract}

Palavras-Chave: Jornalismo Político, Editoriais, Impeachment.

Abstract

This article examines how Folha de S. Paulo and O Estado de S. Paulo expressed their political position on the impeachment of the former president Dilma Rousseff in editorials. The comparative study encompasses quantitative and qualitative approaches of 507 texts ( $F S P=156 ; O E S P=351)$ that mentioned "impeachment" or "impedimento", published between 2015 and 2016. The hypotheses are: 1) Both newspapers build the legitimacy of Rousseff's removal according to the institutional calendar; 2) Both newspapers present similar points of view regarding the process; 3) Both newspapers anchor the legitimacy of Rousseff's impeachment on legal pleas. By using a Content Analysis, we argue that: FSP and OESP mention the impeachment process even before its institutional beginning; both of them are concerned about constructing the impeachment's legitimacy but use diverse arguments to justify it; OESP supports the process as the best exit for the crisis; FSP prefers the president and her vice-president to resign, an action that should be followed by new elections.

Keywords: Political Journalism, Editorials, Impeachment.

\section{A empresa jornalística como ator político: Qual a importância dos editoriais?}

Ao refletir acerca do papel do Jornalismo nas democracias modernas, Bennett argumenta que profissionais e empresas de tal área têm a função de atuar como "adversário politicamente neutro, examinando de forma crítica todos os lados de uma questão, garantindo, consequentemente, a cobertura imparcial do mais amplo leque de matérias ${ }^{\prime \prime}$ (1988: 120). Outros pesquisadores, em trabalhos mais recentes, também dedicaram-

\footnotetext{
${ }^{1}$ Todas as traduções de trechos cujos originais foram publicados em língua estrangeira são de responsabilidade dos autores.
} 
se a examinar o papel adversário desempenhado pelo Jornalismo em relação ao campo político (Clayman 2002; Clayman et al. 2006, 2007; Van Dalen 2012; Eriksson and Ostman 2013). Bennett (1988) destaca, contudo, que mesmo os relatos pretensamente objetivos da seção noticiosa dos periódicos atuam como elementos definidores da realidade social. Nesse sentido, ao longo das últimas décadas, fortaleceu-se a ideia de que a separação entre seções de notícia e de opinião não seria suficiente para impedir determinados direcionamentos na cobertura jornalística (Barros Filho 1995; Chaparro 2003; Kahn and Kenney 2002; Melo 1985; Tang 2011; Traquina 2005).

Não se pode, portanto, descartar a possibilidade de que o processo de confecção das notícias seja afetado pela diretriz ideológica das empresas jornalísticas. Assim, se o editorial confere à instituição jornalística maior liberdade, por exemplo, para expressar apoio a governantes, candidatos, partidos ou demandas temáticas específicas, ele também acaba por alimentar a desconfiança sobre o quanto o periódico estaria priorizando o interesse do próprio jornal em detrimento do interesse público (Meltzer 2007).

Ainda assim, registre-se que a separação (conceitual e espacial) entre notícia e opinião continua a ser uma das estratégias mais relevantes para dar consistência aos princípios do contrato estabelecido entre 0 Jornalismo comercial e o público (Bucci 2000; Chaparro 2003; Marques, Miola, and Siebra 2014; Ribeiro 2003). Em outras palavras, tomando-se um horizonte eminentemente normativo, pode-se dizer que:

Um dos elementos essenciais de uma imprensa imparcial é a parede impenetrável entre as páginas editoriais e aquelas dedicadas às notícias. (...) Enquanto as crenças políticas dos donos e editores de jornais são claramente articuladas nas páginas opinativas, suas visões não devem se infiltrar nas notícias (Kahn; Kenney, 2002: 381).

O editorial - definido como texto não assinado, escrito por profissionais diretamente designados pela direção do jornal com o intuito de representar a opinião da empresa (Alves Filho 2006; Armañanzas and Nocí 1996; Beltrão 1980; Moraes 2007) -, por natureza, contribui para a tentativa de preservar tal distinção entre o relato dos fatos, de um lado, e a tomada de posição, de outro. Ou seja, o texto editorial adota regras distintas daquelas observadas quando da elaboração de materiais noticiosos. São duas as diferenças elementares: não se exige, de tal manifestação opinativa, equilíbrio na abordagem dos fatos; e, por representar a perspectiva da empresa, o editorial torna evidente a seguinte condição dos periódicos: agentes autônomos e dotados de interesse no que concerne a temas que circulam na arena pública (Eilders 1999; Meltzer 2007).

A esta altura, é preciso discutir a função político-mercadológica dos editoriais. Em primeiro lugar, ressaltese que os textos de opinião institucional ajudam a diferenciar os jornais entre si. Isto é, em um processo mimético de padronização da seção noticiosa (Breed 1955; Ramonet 1999), o tom da opinião da empresa jornalística influencia (a) a relação da instituição com sua audiência (leitores que concordam com as visões de mundo do periódico podem se tornar assinantes; ou assinantes que divergem podem cancelar o serviço) (Clark 2014; Giobbe 1994; Scarrow and Borman 1979; Staff 2007); (b) a interação entre o jornal e seus profissionais, uma vez que posturas políticas podem exercer controle direto ou indireto sobre a rotina de trabalho dos jornalistas; dito de forma mais clara, o endosso do jornal a uma determinada agremiação ou candidato pode constranger os repórteres quando eles elaboram conteúdos para as seções noticiosas (Gieber 1956; Sigelman 1973; Soloski 1999); (c) a negociação da empresa jornalística com agentes do 
campo político e econômico (que podem considerar o jornal um agente hostil ou aliado) (Billeaudeaux et al. 2003; Chiang and Knight 2008). Assim, o editorial também tem a prerrogativa de destacar a empresa como líder de opinião - seja para seus leitores, para políticos, para agentes econômicos, para jornalistas ou, mesmo, para jornais de menor porte, que costumam se espelhar nos quality papers² (Breed, 1955).

Em segundo lugar, por meio dos editoriais, o periódico tem a oportunidade de exercer um tipo de autonomia concernente não apenas ao posicionamento de sua preferência, mas, também, quanto às amarras impostas pela agenda noticiosa cotidiana. Em outras palavras, tal gênero textual é capaz de pautar o público sobre questões que se encontram fora da agenda imediata do noticiário (Eilders 1999; Lasch 1995). A noção de critérios de editorialidade (Mont'Alverne and Marques 2016), nesse sentido, ajuda, em parte, a dar conta do fenômeno da formação da agenda editorial, já que a lógica a reger o texto editorial é distinta daquela do material noticioso. Em consonância com a literatura sobre agenda-setting (McCombs 2005; McCombs and Shaw 1972; Shaw 1979; Shehata and Strömbäck 2013; Weaver 2015), é possível argumentar, por conseguinte, que os editoriais sinalizam quais questões o jornal julga prioritárias, oferecendo à audiência e às elites política e econômica um leque de assuntos (Izadi and Saghaye-Biria 2007; Melo 1985).

Assim, uma vez que o editorial jornalístico se mostra um elemento que pode revelar (a) como é construída a interpretação ou a perspectiva da instituição acerca de determinado fato; (b) quais estratégias são utilizadas pela empresa jornalística quando ela reivindica posição de autoridade junto à audiência e ao campo político; e (c) as possíveis transições das opiniões/posicionamentos do jornal em relação às pautas no curso do tempo, o estudo da voz institucional das publicações jornalísticas se mostra fundamental para as investigações nas áreas de Comunicação Política e de Teorias do Jornalismo.

Dentre as pesquisas que abordam empiricamente as posturas políticas das empresas jornalísticas (Eilders 1999; Pratte and Whiting 1986), estão trabalhos que se dedicam não somente a examinar a inclinação dos editoriais a favor de determinados candidatos (F. Azevedo 2016; Kahn and Kenney 2002), mas que, também, esforçam-se para compreender os efeitos de tais textos sobre o comportamento eleitoral do público (Chiang and Knight 2008; Druckman and Parkin 2005; Kahn and Kenney 2002; Scarrow and Borman 1979). No caso brasileiro, há trabalhos que estudam como os editoriais constroem a imagem pública de agentes do campo político (Costa 2009; Mont'Alverne and Marques 2013); ou de instituições do Estado (F. A. Azevedo 2005; F. A. Azevedo and Chaia 2008); ou que pesquisam as narrativas elaboradas acerca de determinado tema de interesse coletivo (Miguel and Coutinho 2007; Nunes Neto 2012; Pereira 2011). Há, ainda, estudos dedicados a examinar a rotina de produção dos editoriais (Guerreiro Neto 2016).

Já o trabalho ora apresentado tem como objetivo examinar os padrões de cobertura editorial quando está em pauta um processo político da maior importância na história brasileira recente, a saber, o impeachment da ex-presidente Dilma Rousseff. 0 estudo comparativo aqui delineado abrange materiais publicados nos anos de 2015 e 2016 pelos jornais Folha de S. Paulo (FSP) e O Estado de S. Paulo (OESP). No total, foram inventariados 507 editoriais que mencionam os termos "impeachment" ou "impedimento". Empiricamente, pretende-se, em um primeiro momento, verificar a frequência com a qual os periódicos trataram o assunto, levando-se em conta o trâmite temporal do processo nas arenas institucionais. Em seguida, os textos

\footnotetext{
2 Em consonância com Azevedo (2016), considera-se que os "quality papers" são publicações com forte impacto no campo político, no debate das questões públicas e junto aos segmentos da opinião pública mais bem informados. Além disso, considera-se que as características elencadas por Hallin e Mancini (2004) para um jornal se constituir como tal também são alcançadas no caso de FSP e OESP, a exemplo de dirigirem-se às elites políticas, econômicas e intelectuais e conferir maior preponderência ao noticiário político.
} 
publicados nos meses decisivos do processo de impeachment foram investigados qualitativamente a fim de perceber em que argumentos os jornais se ancoraram para construir (ou questionar) a legitimidade do afastamento da então presidente.

Na próxima seção, são apresentadas as estratégias metodológicas e as hipóteses do trabalho. Logo depois, a apresentação e a análise dos dados passam a ter lugar privilegiado. Mais adiante, discutem-se as descobertas da investigação e, por fim, são expostas as conclusões da pesquisa.

\section{Estratégias metodológicas e hipóteses}

Antes mesmo de Dilma Rousseff ser reeleita para a Presidência da República, em 2014, o cenário político brasileiro se mostrava desfavorável para o governo da então mandatária, sobretudo por conta do desgaste sofrido pelo Partido dos Trabalhadores desde o início da Operação Lava Jato ${ }^{3}$. Apesar de a coligação que

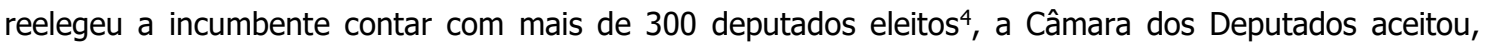
apenas no nono mês do segundo mandato de Dilma, avaliar o pedido de impeachment assinado pelos juristas Hélio Bicudo, Janaína Pascoal e Miguel Reale Junior. A peça alegava como justificativa fundamental a acusação de que Dilma teria cometido crime de responsabilidade - o que foi questionado por meio de argumentos diversos 5 .

De modo paralelo ao processo de impeachment, o governo teve de lidar com o agravamento da crise econômica no país e com um cenário marcado por denúncias de corrupção envolvendo tanto aliados do governo, quanto integrantes da oposição. Da abertura da investigação (em dezembro de 2015) até ser aprovado o afastamento definitivo da ex-presidente (ocorrido em agosto de 2016), passou-se menos de um ano.

Assim sendo, este trabalho se interessa por investigar de que maneira os editoriais de dois quality papers de relevância nacional - a saber, O Estado de S. Paulo (OESP) e a Folha de S. Paulo (FSP) - abordaram o processo de impeachment de Dilma em seus editoriais ${ }^{6}$. A opção por investigar os periódicos em tela leva em conta a circulação nacional de ambos e o fato de eles disputarem fatias de mercado semelhante, o que torna mais interessante a comparação acerca de suas respectivas abordagens editoriais. Sublinhe-se, ainda, que as duas empresas jornalísticas enfatizam o acompanhamento das dinâmicas políticas em âmbito federal e que detêm prestígio junto às elites políticas e econômicas ${ }^{7}$. Além disso, OESP e FSP exercem de formas distintas a opinião institucional. Enquanto o primeiro possui larga tradição em se posicionar claramente sobre temas de interesse nacional ou candidaturas (Capelato and Prado 1980; Sodré 1999), o segundo

\footnotetext{
${ }^{3}$ Mais informações disponíveis em http://lavajato.mpf.mp.br/entenda-o-caso, acessado em 09/04/2017.

${ }^{4}$ Disponível em http://bit.ly/1zx5tTI, acessado em 08/02/2017.

${ }^{5} \mathrm{~A}$ alegação principal se referiu às chamadas "pedaladas fiscais" e à edição de decretos de suplementação orçamentária sem autorização do Legislativo. A defesa afirmou que os decretos não autorizaram um aumento de gastos, porque apenas remanejaram dinheiro de despesas já previstas e autorizadas pelo Congresso. Mais detalhes em http://www12.senado.leg.br/noticias/materias/2016/05/02/especialistas-entendem-que-dilma-cometeu-crime-deresponsabilidade e em http://brasil.elpais.com/brasil/2016/08/28/politica/1472412248 958761.html, acessado em 12/02/2017.

${ }^{6}$ Os dois jornais estão dentre os cinco com maior tiragem no Brasil, de acordo com dados de 2015. A FSP teve média de circulação de 189.254 edições, enquanto a média de OESP foi de 157.761. Disponível em http://www.anj.org.br/maioresjornais-do-brasil/, acessado em 12/06/2016.

${ }^{7}$ De acordo com o mídia kit dos periódicos, 80\% dos leitores de OESP são das classes A e B. No caso da FSP, $60 \%$ dos leitores pertencem a estas classes. Disponível em http://publicidade.estadao.com.br/estadao/estadao-dados-demercado/ e em http://www.publicidade.folha.com.br/folha/perfil do leitor.shtml, acessado em 15/02/ 2017.
} 
periódico evita alinhar-se a candidatos ou a grupos políticos, apresentando oscilações de posição política ao longo de sua trajetória (Dias 2012; Lattman-Weltman 2003; Pilagallo 2012).

A coleta do material foi realizada a partir do website de cada publicação: as páginas da versão impressa foram salvas em formato PDF. Os textos editoriais nos quais os termos "impeachment" ou "impedimento" foram encontrados passaram por novo filtro, o que implicou leitura integral do conteúdo a fim de eliminar, por exemplo, casos em que a palavra "impedimento" apareceu em contexto alheio ao processo de afastamento do cargo da ex-presidente.

As hipóteses que guiam a investigação empírica do artigo são as seguintes:

Os editoriais de FSP e OESP: H1) Constroem, de forma sincronizada com o desenvolvimento do processo de impeachment nas esferas institucionais, a ideia de legitimidade do afastamento de Dilma; H2) Apresentam pontos de vista semelhantes em relação ao impeachment; H3) Ancoram a legitimidade do afastamento de Dilma, essencialmente, em argumentos jurídicos.

Partindo, portanto, do texto editorial como unidade de análise, o artigo apresenta uma análise dos casos nas dimensões quantitativa e qualitativa. Para a análise com ênfase quantitativa, o corpus empírico considerado é constituído pelos 507 textos editoriais de Folha de S. Paulo (FSP) ( $n=156)$ e $O$ Estado de $S$. Paulo (OESP) $(n=351)^{8}$ que mencionaram os termos "impeachment" ou "impedimento" entre Janeiro de 2015 e Dezembro de 2016. Essa parte da pesquisa tem como meta apresentar um panorama da cobertura e de seu desenvolvimento de acordo com o contexto institucional do processo em pauta. Assim, apresentase o volume de editoriais durante todo o período observado e aplica-se um cruzamento que envolve a frequência de publicações e o desenvolvimento do processo em âmbito institucional.

Em relação à dimensão qualitativa, a variável dependente é o posicionamento dos jornais quanto à legitimidade ou não do afastamento de Dilma. As variáveis independentes são três: a) Argumento Legitimador utilizado no editorial; b) Saídas apontadas para a situação política; c) Consequências do impeachment. Estas três variáveis foram observadas do ponto de vista dicotômico e categórico, a fim de apreender, por meio de Análise de Conteúdo (Bardin 1977; Bauer 2002; Cavalcante, Calixto, and Pinheiro 2014; Krippendorff 2004; Lacy et al. 2015), de que maneira os jornais construíram seus respectivos discursos ao abordarem o afastamento de Dilma. A definição das categorias, o que permite identificar os indicadores que compõem cada variável, deu-se a partir de observação empírica dos textos. Ou seja, a leitura préanalítica do corpus permitiu mapear pontos de natureza diversa relacionados ao processo político da época, a exemplo de menções à Constituição, às alegadas "pedaladas" fiscais etc.

Vale ressaltar que um mesmo editorial pode trazer mais de um Argumento Legitimador, Saída para a Situação Política ou Consequência do Impeachment. Adotou-se tal estratégia com o intuito de evitar perder o registro de categorias que aparecem mais de uma vez na mesma peça. Sublinhe-se que as próprias características do gênero editorial fazem com que os textos tenham estrutura argumentativa complexa e plural, tendo em vista que o intuito é convencer o público e estabelecer diálogo com agentes políticos. É frequente, assim, que diferentes aspectos de uma mesma situação sejam apresentados, com mobilização de justificativas de ordens distintas (Campos 2014). Assim, não seria razoável limitar o registro a apenas

\footnotetext{
${ }^{8} \mathrm{O}$ jornal $O$ Estado de $S$. Paulo publica, na página A3, três editoriais por dia. Há, ainda, um editorial econômico, que não dispõe da mesma visibilidade dos outros, sendo publicado no caderno de Economia, de terça a domingo. Para este texto, analisam-se apenas editoriais publicados na página A3. Já a Folha de S. Paulo traz dois editoriais diariamente, na página A2 - a quantidade de textos pode ser alterada em casos excepcionais, nos quais o jornal sai com um só editorial mais longo.
} 
uma categoria por peça completa, desconsiderando a quantidade de categorias efetivamente encontradas. Tal opção teria implicado uma simplificação forçada dos textos, causando prejuízos aos resultados e à discussão empreendidos no artigo.

Após uma primeira rodada de classificação, realizada em conjunto e por meio de debate entre os pesquisadores, foi elaborado a tabela abaixo, o qual detalha as variáveis independentes categóricas que serviram de baliza para a análise qualitativa. As categorias foram criadas lançando mão do método indutivo, de acordo com a pré-análise necessária para que se opere a Análise de Conteúdo. A necessidade de desenvolver tais categorias se dá uma vez que ainda não foram propostas, na literatura, outras semelhantes que sejam dedicadas a trabalhar com a especificidade do editorial como o gênero jornalístico - ainda mais tratando-se de um evento singular, como o impeachment. Ademais, as variáveis expostas abaixo são fundamentais para construir - e para sustentar - posicionamentos acerca de questão controversa e atípica, acerca da qual os periódicos possuem interesse nos desdobramentos. Não é uma categorização, portanto, que se pretende generalizável. Na realidade, o intuito de sua especificidade é, justamente, permitir que a tipologia se adeque às características do fenômeno analisado.

Tabela 1: Variáveis independentes e suas categorias

\begin{tabular}{|c|c|}
\hline ARGUMENTO LEGITIMADOR & $\begin{array}{l}\text { - Normas legais (Menção à Constituição e a outras leis) } \\
\text { - Crime de responsabilidade } \\
\text { - Voz do povo (Avaliação do governo, protestos) } \\
\text { - Crise econômica } \\
\text { - Crise política } \\
\text { - Corrupção e fisiologismo (uso da máquina pública, repercussão } \\
\text { de denúncias e escândalos) } \\
\text { - Outro }\end{array}$ \\
\hline $\begin{array}{l}\text { SAÍDAS PARA A SITUAÇÃO } \\
\text { POLÍTICA }\end{array}$ & $\begin{array}{l}\text { - Impeachment } \\
\text { - Renúncia } \\
\text { - Novas eleições } \\
\text { - Algo deve ser feito (sem que o jornal especifique o quê) } \\
\text { - Outra }\end{array}$ \\
\hline $\begin{array}{l}\text { CONSEQUÊNCIAS } \\
\text { IMPEACHMENT }\end{array}$ & $\begin{array}{l}\text { - Instabilidade política } \\
\text { - Instabilidade econômica } \\
\text { - Melhora do cenário econômico } \\
\text { - Melhora do cenário político } \\
\text { - Melhora geral } \\
\text { - Futuro incerto } \\
\text { - Outra }\end{array}$ \\
\hline
\end{tabular}

Fonte: os autores.

Para a análise qualitativa, que permite verificar o posicionamento dos editoriais sobre o referido processo, decidiu-se selecionar três meses cruciais: Dezembro de 2015 (quando a solicitação de impedimento foi aceita pelo então presidente da Câmara, o deputado Eduardo Cunha, do PMDB); Abril de 2016 (quando o 
plenário da Câmara aprova a abertura do processo de impeachment de Dilma); e Agosto de 2016 (quando o Senado Federal concluiu o processo e Michel Temer assumiu o posto de chefe do Executivo de forma definitiva). O período compreende 49 editoriais da FSP e 105 de OESP. A escolha de tais meses se deveu à necessidade de reduzir o número de editoriais para a análise qualitativa, uma vez que tal passo implicou leitura integral dos textos selecionados pelos pesquisadores e classificação de acordo com as variáveis apresentadas anteriormente. Ressalte-se que o processo analítico ocorreu após treinamento acerca das categorias implicadas em cada variável, bem como utilização de livro de códigos ${ }^{9}$. Cada grupo classificado foi revisto por outro pesquisador ${ }^{10}$.

\section{Análise}

A análise dos dados está dividida em três partes. Na primeira delas, revela-se o volume de editoriais publicados entre janeiro de 2015 e dezembro de 2016, utilizando-se uma linha descritiva que permite observar, dentre outras coisas, a oscilação temporal da cobertura editorial acerca do afastamento de Dilma Rousseff da Presidência. A seguir, a intenção é compreender em que medida houve sincronia entre o volume de publicações dos editoriais que tratam do impeachment e a timeline dos acontecimentos institucionais (para isso, consideram-se apenas os passos do processo no âmbito do Congresso). Já a abordagem qualitativa permite detalhar a postura política dos periódicos acerca da legitimidade ou não do afastamento da ex-presidente.

\section{Volume de editoriais publicados ao longo do período (linha descritiva)}

Tendo em vista a discussão teórica realizada e a estrutura metodológica definida anteriormente, a análise se inicia pela observação da frequência de publicações dos editoriais, verificando-se a presença dos termos "impeachment" e "impedimento" nos textos de cada periódico.

\footnotetext{
${ }^{9} \mathrm{O}$ livro de códigos está disponível sob demanda aos autores.

10 Uma vez concluída a categorização dos editoriais por parte de cada pesquisador, foi realizada uma dupla conferência de 36 editoriais (sendo 18 de cada jornal em estudo), o que equivale a $18 \%$ dos textos que compõem a amostra desta parte da pesquisa.
} 
Figura 1: Volume mensal de editoriais mencionando "impeachment" ou "impedimento" - FSP e OESP

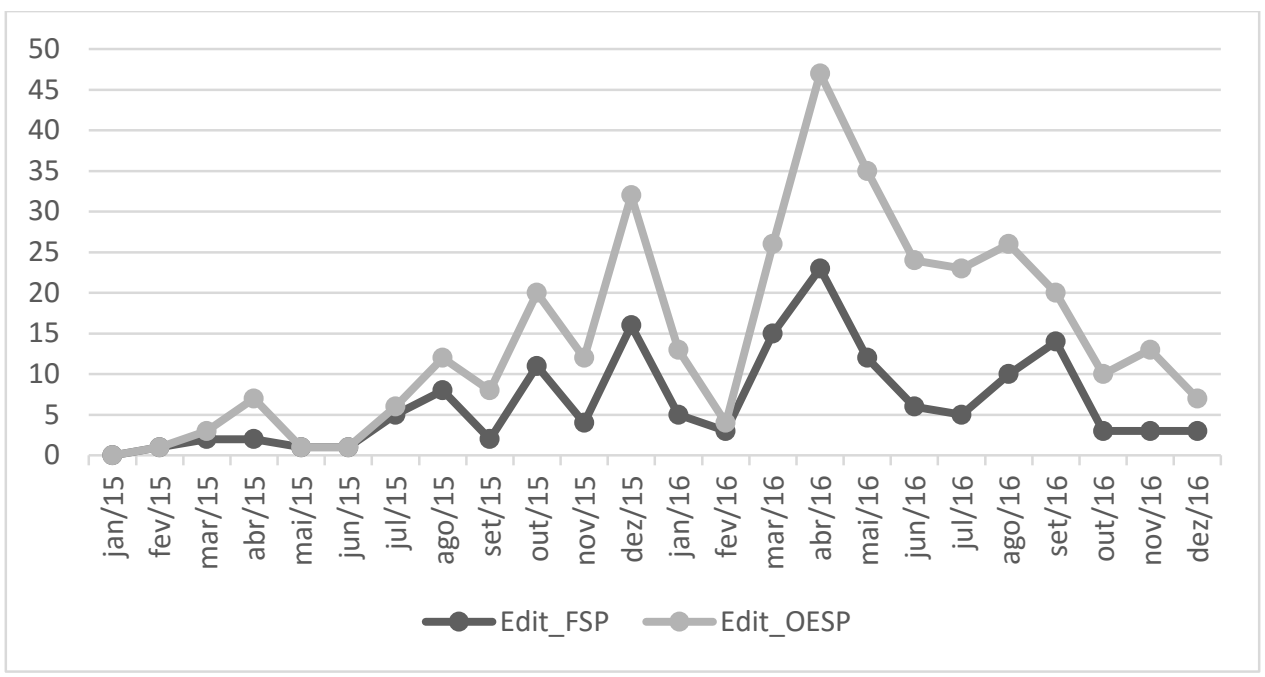

Fonte: os autores

No que se refere à Folha de S. Paulo, percebe-se, a partir da figura 1, que o jornal começa a tratar do tema em seus editoriais já no mês de fevereiro de 2015, poucos dias após Dilma ser empossada para o segundo mandato. A FSP segue um movimento oscilante, mas com picos de publicações no intervalo de janeiro de 2015 e setembro de 2016.

Mais especificamente, conforme avança a expectativa de votação do processo de afastamento de Dilma na Câmara dos Deputados, há um aumento evidente da frequência de publicação de editoriais - sobretudo entre os meses de março e maio de 2016, quando a FSP publicou um total de 50 editoriais sobre o processo. No geral, ao longo dos dois anos, a Folha apresentou uma média mensal de 6,5 editoriais que trataram do impedimento de Dilma. Aponta-se, ademais, que os editoriais a trazerem as palavras-chave "impeachment" ou "impedimento" representam $10,67 \%$ do total de editoriais publicados pelo jornal durante período aqui analisado. Entre janeiro de 2015 e dezembro de 2016, a FSP publicou 1462 editoriais no total.

Já se for observada a dinâmica de publicação editorial de OESP, constata-se que tal periódico seguiu, de modo geral, o mesmo caminho da FSP: aliás, as linhas dos dois periódicos na figura 1 obedecem a padrões similares durante todo o período analisado - não obstante a diferença em valores absolutos.

Registre-se que, apesar de ambos os jornais começarem a tratar do assunto em fevereiro de 2015 e apresentarem picos praticamente nos mesmos meses, OESP tem queda no número de editoriais sobre o impeachment entre agosto e setembro de 2016, movimento contrário àquele do jornal concorrente neste período.

Em relação à quantidade de editoriais mencionando os termos de busca da pesquisa, OESP apresentou uma média de 14,6 textos por mês, o que representou $16 \%$ do total de editorais publicados entre janeiro de 2015 e dezembro de 2016, quando OESP publicou 2193 editoriais no total. Os números, então, indicam que O Estado de S. Paulo se dedicou a abordar o afastamento de Dilma com mais frequência que a Folha. 
Volume de publicações vs. timeline dos acontecimentos institucionais

Com o intuito de verificar se houve alguma relação entre o ritmo de publicação dos editoriais e o avanço institucional do processo político no âmbito do Congresso, fez-se um levantamento cronológico - a partir de materiais publicados em materiais jornalísticos e nos portais da Câmara dos Deputados e do Senado Federal - dos acontecimentos oficiais que marcaram o impeachment, conforme a tabela 2. Ressalte-se que houve um recorte a fim de considerar apenas os passos que se desenvolveram no âmbito do Congresso Nacional (ou diretamente atrelados a tal instituição), encarregado de decidir sobre o afastamento da Presidente responsável, portanto, por desempenhar papel crucial no encaminhamento do processo.

Tabela 2: Cronologia do processo institucional de impeachment

\begin{tabular}{|c|c|}
\hline MÊS & ACONTECIMENTOS / PASSOS DO PROCESSO \\
\hline Setembro/15 & Formalização do pedido de impeachment por juristas \\
\hline Dezembro/15 & $\begin{array}{l}\text { Aceitação do pedido de impeachment pelo então Presidente da } \\
\text { Câmara, deputado Eduardo Cunha }\end{array}$ \\
\hline Março/16 & $\begin{array}{l}\text { Formação da Comissão Especial para analisar o pedido de } \\
\text { impeachment na Câmara }\end{array}$ \\
\hline Abril/16 & $\begin{array}{l}\text { O relator (deputado Jovair Arantes) apresenta parecer favorável ao } \\
\text { impeachment de Dilma Rousseff }\end{array}$ \\
\hline Abril/16 & Comissão Especial vota favoravelmente a parecer do impeachment \\
\hline Abril/16 & Plenário da Câmara aprova a abertura do processo de impeachment \\
\hline Abril/16 & Encaminhamento do processo ao Senado \\
\hline Abril/16 & $\begin{array}{l}\text { Formação da Comissão Especial para analisar o pedido de } \\
\text { impeachment no Senado }\end{array}$ \\
\hline Abril/16 & Instalação da Comissão Especial no Senado Federal \\
\hline Maio/16 & $\begin{array}{l}\text { O relator (senador Antonio Anastasia) apresenta parecer favorável à } \\
\text { continuidade do processo de impeachment }\end{array}$ \\
\hline Maio/16 & Comissão Especial vota favoravelmente a parecer do impeachment \\
\hline Maio/16 & Senado autoriza a abertura do processo de impeachment \\
\hline Maio/16 & Dilma é afastada do cargo de Presidente por 180 dias \\
\hline Maio/16 & Michel Temer assume o cargo de Presidente na condição de interino \\
\hline Agosto/16 & $\begin{array}{l}\text { O relator Antonio Anastasia apresenta parecer favorável ao } \\
\text { impeachment de Dilma Rousseff }\end{array}$ \\
\hline Agosto/16 & Relatório é aprovado pela Comissão Especial do Senado \\
\hline Agosto/16 & Plenário do Senado aprova o parecer elaborado pela Comissão \\
\hline Agosto/16 & Início da etapa final do julgamento no Senado Federal \\
\hline Agosto/16 & Plenário do Senado aprova o impeachment de Dilma Rousseff \\
\hline
\end{tabular}

Fonte: os autores (a partir de informações oficiais). 
Tendo em vista os eventos acima indicados, decidiu-se por investigar a relação entre (a) o volume de editoriais publicados e (b) o volume de eventos que caracterizaram o andamento institucional do processo. Ou seja, deseja-se depreender se houve alguma correspondência entre a agenda do campo políticoparlamentar e a agenda editorial de FSP e OESP.

Figura 2: Relação entre cada jornal e a timeline dos acontecimentos institucionais

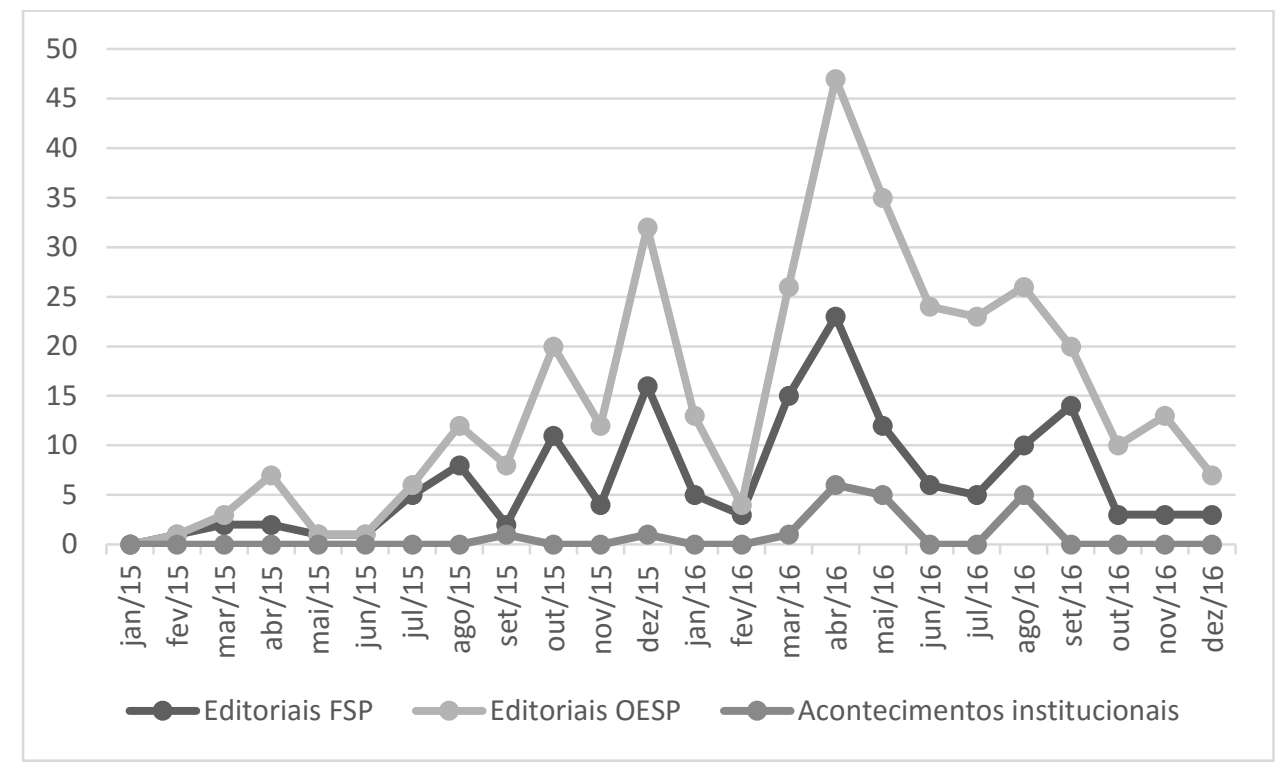

Fonte: os autores

Ao analisar os casos individualmente, percebe-se que os jornais cobriram o tema "impeachment" em seus editoriais mesmo quando não havia qualquer movimentação institucional em torno da proposta - conforme observado anteriormente neste artigo. Entretanto, os dois periódicos intensificam esse tipo de publicação quando há maior incidência de acontecimentos oficiais, o que é apontado pelas curvas ascendentes nos meses de abril e de agosto de 2016, quando ocorreram, respectivamente, 6 e 5 eventos ligados ao processo em tela (as maiores ocorrências). Isso contribui para diagnosticar uma relação positiva entre o volume de publicações dos dois periódicos e o avanço do processo em termos institucionais.

Observando-se os dados de forma agregada (figura 2), percebe-se que (a) os dois jornais mantêm certa sintonia entre si quanto à frequência de publicações de editoriais que abordam o afastamento de Dilma e que (b) essa lógica de publicação mantém paralelo com o desenrolar dos acontecimentos institucionais. Confirma-se, então, a existência de uma relação positiva entre a frequência da agenda editorial e da agenda política nos dois jornais, mesmo que não haja uma correspondência plena, já que os jornais pautaram o impeachment antes mesmo que o processo tivesse início e não seguiram o mesmo volume de editoriais acerca da temática no mês de maio, que abrigou cinco eventos institucionais.

Os editoriais e a postura política das empresas jornalísticas: a questão da legitimidade do impeachment

Com o objetivo de investigar qualitativamente a postura política dos editoriais a partir das variáveis empregadas na pesquisa, apresentam-se, primeiramente, os dados descritivos acerca das ocorrências das 
variáveis - lembrando que se optou por mensurar a incidência de três tipos de variáveis, a saber, "Argumento Legitimador", "Saídas para a situação política" e "Consequências do Impeachment".

Em "Argumento Legitimador", a ideia é verificar quais foram as razões mais recorrentemente utilizadas nos editoriais dos dois jornais a fim de justificar a necessidade (ou não) de afastamento de Dilma Rousseff.

Tabela 2: Volume de editoriais apresentando "Argumento Legitimador"

\begin{tabular}{|c|c|c|c|}
\hline \multicolumn{2}{|l|}{ Jornal } & \multirow{2}{*}{$\begin{array}{l}\text { Frequência } \\
42\end{array}$} & \multirow{2}{*}{\begin{tabular}{|l|} 
Percentual \\
85,7
\end{tabular}} \\
\hline \multirow{2}{*}{ FSP } & Editoriais com Argumento Legitimador & & \\
\hline & $\begin{array}{l}\text { Total de editoriais que mencionam as } \\
\text { palavras-chave no período }\end{array}$ & 49 & 100,0 \\
\hline \multirow{2}{*}{ OESP } & Editoriais com Argumento Legitimador & 91 & 86,7 \\
\hline & $\begin{array}{l}\text { Total de editoriais que mencionam as } \\
\text { palavras-chave no período }\end{array}$ & 105 & 100,0 \\
\hline
\end{tabular}

Fonte: os autores.

A tabela 3 aponta o predomínio do uso de "Argumento Legitimador" do impeachment, que está presente em mais de $85 \%$ dos textos dos dois jornais. Isso significa que houve uma preocupação constante dos periódicos em construir (ou questionar) a legitimidade do afastamento de Dilma. É importante, aliás, indicar a semelhança percentual que as duas publicações apresentam quando fundamentam a legitimidade do impedimento de Dilma. Deve-se observar, porém, que FSP e OESP divergiram quanto à natureza da argumentação utilizada para indicar, na opinião de cada periódico, a necessidade do afastamento da então presidente. É o que se verifica a partir da tabela abaixo ${ }^{11}$.

Tabela 3: Tipos de "Argumentos legitimadores" adotados nos editoriais

\begin{tabular}{|c|c|c|c|c|}
\hline Tipo de Argumento Legitimador & FSP & Percentual & OESP & Percentual \\
\hline Crime de responsabilidade & 4 & 5,1 & 27 & 15,5 \\
\hline Crise econômica & 20 & 25,6 & 37 & 21,1 \\
\hline Crise política & 14 & 18 & 14 & 8 \\
\hline Normas legais & 16 & 20,5 & 27 & 15,5 \\
\hline Voz do povo & 6 & 7,7 & 26 & 14,8 \\
\hline Corrupção e fisiologismo & 10 & 12,8 & 24 & 13,7 \\
\hline Outro $^{12}$ & 8 & 10,3 & 20 & 11,4 \\
\hline
\end{tabular}

\footnotetext{
11 Trecho de editorial de OESP que traz, como Argumentos Legitimadores, as categorias "crise econômica", "crime de responsabilidade" e "uso da máquina pública": "Não há como alojar em compartimentos separados o fracasso dos investimentos em infraestrutura, a depredação de estatais, os crimes investigados na Operação Lava Jato, as pedaladas fiscais, a destruição das finanças públicas e a estagflação. O processo de impeachment, o rebaixamento do crédito e a vulnerabilidade do Brasil à alta dos juros externos são pedaços da mesma história" (Dilma, o Fed e o rebaixamento, 18 de dezembro de 2015: A3).

12 Dentre os Argumentos Legitimadores agrupados na categoria "Outro", estão "Alegada incompetência do governo Dilma", "Ausência de condições de governabilidade" e "Sectarismo ideológico de Dilma".
} 


\begin{tabular}{|l|l|l|l|l|}
\hline Total de Argumentos Legitimadores & 78 & 100,0 & 175 & 100,0 \\
\hline
\end{tabular}

Fonte: os autores

Não obstante o fato de tanto Folha de S. Paulo quanto O Estado de S. Paulo acionarem "crise econômica" como Argumento Legitimador mais recorrente (justificativa correspondente a $25,6 \%$ do total de argumentos apresentados pela FSP e a $21,1 \%$ deles em OESP), os jornais se comportam diferentemente quando outros indicadores são levados em conta.

É possível perceber que os Argumentos Legitimadores mobilizados por OESP compõem uma espécie de "conjunto da obra", pois enfatizam quatro aspectos principais, na seguinte ordem: "crise econômica", "crime de responsabilidade", "normas legais" "corrupção e fisiologismo" e "voz do povo". No caso da FSP, o segundo argumento mais acionado, após "crise econômica", é "normas legais", seguido de "crise política"13. Ressaltese que a Folha faz poucas referências à justificativa "crime de responsabilidade" - aliás, esta é a categoria menos mencionada na FSP e a segunda mais recorrente nos editoriais de OESP. OESP, inclusive, trata de "crime de responsabilidade" na mesma proporção do que faz com "normas legais", indicando a mobilização de um conjunto de justificativas jurídicas como Argumentos Legitimadores.

Parte-se, agora, para a exploração da categoria "Saídas para a situação política". Ao longo dos meses examinados, FSP e OESP cogitaram diferentes possibilidades para resolver o impasse político em que o país se encontrava (desde a defesa vaga de que "algo deve ser feito" até o diagnóstico sobre a necessidade do impeachment). Os dados a seguir permitem comprovar a postura das duas publicações.

Tabela 4: Presença de "Saídas para a situação política" nos editoriais

\begin{tabular}{|c|c|c|c|}
\hline \multicolumn{2}{|l|}{ Jornal } & \multirow{2}{*}{$\begin{array}{l}\text { Frequência } \\
14\end{array}$} & \multirow{2}{*}{$\begin{array}{l}\text { Percentual } \\
28,6\end{array}$} \\
\hline \multirow{2}{*}{ FSP } & Editoriais com "Saídas" & & \\
\hline & $\begin{array}{l}\text { Total de editoriais que mencionam as palavras- } \\
\text { chave no período }\end{array}$ & 49 & 100,0 \\
\hline \multirow{2}{*}{ OESP } & Editoriais com "Saídas" & 29 & 27,6 \\
\hline & $\begin{array}{l}\text { Total de editoriais que mencionam as palavras- } \\
\text { chave no período }\end{array}$ & 105 & 100,0 \\
\hline
\end{tabular}

Fonte: os autores.

Os jornais mantêm percentuais semelhantes no tocante à proposição de soluções para a situação política do país (aproximadamente $28 \%$ dos editoriais de FSP e OESP mencionam algum tipo de "saída"). A recorrência de sugestões de "Saídas" em editoriais, todavia, é consideravelmente menor que aquela de Argumentos Legitimadores (que alcançou mais de $85 \%$, de acordo com o que se percebeu anteriormente).

\footnotetext{
13 Trecho de editorial da FSP que mobiliza como "Argumento Legitimador" a categoria "normas legais": "A presidente se permitiu afirmar a jornalistas estrangeiros que o processo em curso representa uma 'fraude jurídica e política'. Se tivesse mais apreço pela verdade e pela imagem do país, poderia lançar suspeitas contra muitos deputados e questionar suas motivações, mas jamais difundir a falácia de que as instituições nacionais se acham violentadas. Todo o roteiro seguido até aqui foi acompanhado pelo Supremo Tribunal Federal, e em nenhum momento houve desrespeito à Constituição" (Presidência anômala, 20 de abril de 2016: A2).
} 
Assim, pode-se afirmar, de antemão, que, em muitos momentos, os jornais não apresentam uma sugestão clara sobre que encaminhamentos deveriam ser adotados para resolver a crise. Os dados da tabela seguinte, todavia, mostram que FSP e OESP discordam quanto à solução mais adequada para o impasse político estabelecido no Brasil durante o período.

Tabela 5: Tipos de "Saídas para a situação" adotadas nos editoriais

\begin{tabular}{|l|l|l|l|l|}
\hline Tipo de Saída & FSP & Percentual & OESP & Percentual \\
\hline Impeachment & 2 & 9,5 & 21 & 72,4 \\
\hline Novas eleições & 7 & 33,4 & 2 & 6,8 \\
\hline Renúncia & 6 & 28,6 & 1 & 3,5 \\
\hline Algo deve ser feito & 4 & 19,0 & 1 & 3,5 \\
\hline Outra ${ }^{14}$ & 2 & 9,5 & 4 & 13,8 \\
\hline Total de Saídas & 21 & 100,0 & 29 & 100,0 \\
\hline
\end{tabular}

Fonte: os autores.

Mais de 72\% dos editoriais de OESP que mencionam algum tipo de "saída" defendem o impeachment de Dilma Rousseff. O periódico pouco especula sobre outras possibilidades, o que permite inferir uma posição praticamente fechada do jornal sobre a questão durante os meses investigados ${ }^{15}$. No caso da FSP, a saída mais recorrente é a realização de novas eleições para a Presidência (o que ocorreu em 33\% dos textos que especularam sobre as soluções para o impasse), seguida de perto pela defesa de renúncia - o periódico, aliás, sugere a renúncia tanto de Dilma quanto de Temer ${ }^{16}$. A bem da verdade, a FSP apresenta, frequentemente, estas duas soluções em conjunto (renúncia + eleições), tendo em vista que um novo pleito poderia ser convocado no caso da vacância do cargo de presidente e de vice-presidente.

A última categoria é concernente à avaliação que os dois jornais fazem sobre quais seriam as "Consequências do Impeachment". Dentre as possibilidades cogitadas estão, por exemplo, do aumento da instabilidade política e econômica até uma melhora geral no caso de se confirmar o afastamento de Dilma Rousseff.

Tabela 6: Presença de "Consequências do (não) impeachment" nos editoriais

\begin{tabular}{|l|l|l|l|}
\hline \multicolumn{2}{|l|}{ Jornal } & Frequência & Percentual \\
\hline \multirow{2}{*}{ FSP } & Editoriais com "Consequências" & 10 & 20,4 \\
\cline { 2 - 5 } & $\begin{array}{l}\text { Total de editoriais que mencionam as } \\
\text { palavras-chave no período }\end{array}$ & 49 & 100,0 \\
\hline OESP & Editoriais com "Consequências" & 42 & 40 \\
\hline
\end{tabular}

\footnotetext{
${ }^{14}$ Dentre as saídas agrupadas na categoria "Outra", encontram-se "Afastamento de Dilma, Lula e Cunha da vida política", "União de dois partidos (PMDB e PSDB)" ou "Plebiscito sobre a saída de Dilma".

${ }^{15} \mathrm{Um}$ exemplo dessa postura pode ser encontrado no seguinte trecho, de OESP: "Qualquer decisão do Congresso que acelere a conclusão do processo de impeachment da presidente Dilma Rousseff será muito bem-vinda" ( $O$ preço da interinidade, 4 de agosto de 2016: A3).

${ }^{16}$ Trecho de editorial da FSP a defender a renúncia de Dilma: "Dilma Rousseff deve renunciar já, para poupar o país do trauma do impeachment e superar tanto o impasse que o mantém atolado como a calamidade sem precedentes do atual governo" (Nem Dilma nem Temer, 3 de abril de 2016: A1).
} 


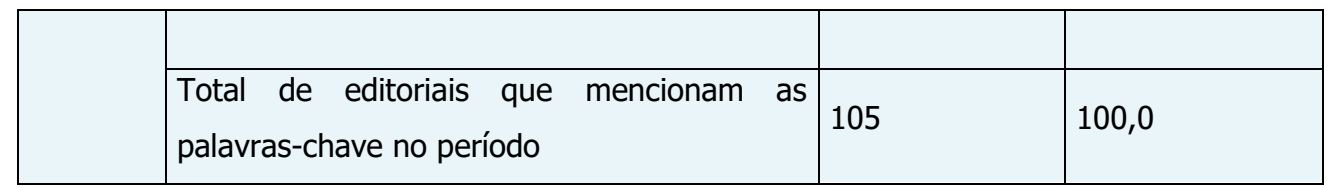

Fonte: os autores.

OESP possui, proporcionalmente, mais editoriais preocupados em abordar as consequências do impeachment (ou as consequências da manutenção de Dilma na Presidência) que seu jornal concorrente: $40 \%$ dos textos veiculados por esta publicação especulam acerca dos resultados decorrentes do processo de afastamento da então mandatária - contra 20,4\% da FSP. De maneira geral, tal resultado pode indicar que OESP enfatiza suas preocupações com o cenário futuro - principalmente na seara econômica, uma vez que a referida empresa jornalística aponta mais benefícios que malefícios a partir da saída de Dilma.

Tabela 7: Consequências do (não) impeachment adotadas nos editoriais

\begin{tabular}{|l|l|l|l|l|}
\hline Tipo de Consequência & FSP & Percentual & OESP & Percentual \\
\hline Instabilidade econômica & 2 & 14,2 & 1 & 2,3 \\
\hline Instabilidade política & 5 & 37,7 & 12 & 27,3 \\
\hline Melhora do cenário econômico & 1 & 7,1 & 15 & 34 \\
\hline Melhora do cenário político & 0 & 0 & 3 & 6,8 \\
\hline Melhora geral & 0 & 0 & 6 & 13,6 \\
\hline Futuro incerto & 4 & 28,6 & 0 & 0 \\
\hline Outra & 2 & 14,2 & 7 & 16 \\
\hline Total de Consequências & 14 & 100,0 & 44 & 100,0 \\
\hline
\end{tabular}

Fonte: os autores.

Dito de outra forma, a consequência mais recorrente projetada por OESP, em 34\% dos editoriais, é a melhora da situação econômica do país. Esse jornal também vê a instabilidade política como uma possível consequência, mas não acredita que o afastamento da mandatária deveria ser evitado por isso - isto é, na perspectiva do jornal ora analisado, o benefício compensaria o custo. OESP abre espaço para apontar outras consequências relacionadas ao caso de o impedimento da Presidente não ocorrer - o país continuaria em trajetória descendente sob os aspectos político e econômico.

Já a FSP, embora apresente a instabilidade política como a maior consequência do impeachment ${ }^{17}$, adota uma postura mais cautelosa em relação à apresentação de consequências. Desse modo, o jornal especula acerca de um futuro incerto, assim como outros cenários caso o impeachment se confirme ou não - inclusive, o jornal sugere alternativas àquelas indicadas pelas categorias estabelecidas neste artigo, a exemplo da consequência de que o "Enfraquecimento do governo Dilma mesmo que escape do impeachment" ou de que haveria "Aprofundamento do populismo lulopetista caso o afastamento fosse rejeitado". A melhora do cenário econômico (item que foi o mais recorrente no caso de OESP) fica em último lugar dentre as

17 Exemplo de trecho publicado em editorial da FSP que aponta a instabilidade política como Consequência do impeachment. "A crise política, pode-se perceber, não terá seu último capítulo na decisão sobre o impeachment de Dilma. Mesmo que o governo vença no Legislativo, novos problemas se abaterão sobre a presidente e sobre Temer. Um eventual governo do peemedebista começaria marcado pela incerteza" (Crise ininterrupta, 8 de abril de 2015: A2). 
consequências listadas pela FSP, o que denota uma nítida diferença acerca das prioridades de cada publicação.

\section{Discussão}

A primeira hipótese do trabalho sugeriu que os dois jornais constroem, de forma sincronizada com o desenvolvimento do processo de impeachment nas esferas institucionais, a ideia de legitimidade do afastamento de Dilma. A partir dos dados coletados, é possível defender que a proposição foi comprovada. No que concerne ao agendamento do processo político em tela nos editoriais dos periódicos analisados, verifica-se que o afastamento de Dilma já vinha sendo discutido por FSP e OESP antes de o processo de impeachment ter início nas arenas institucionais. Mesmo assim, uma vez que o pedido de afastamento começa a ser avaliado pela Câmara e segue para o Senado, é natural que o interesse editorial acompanhe o desenrolar da situação, como ocorreu nos casos observados.

A sincronia com o ritmo dos acontecimentos, contudo, parece relativizar o que parte dos autores utilizados como referência neste artigo apontaram. Mesmo que outros trabalhos apontem para a possibilidade de os editoriais conferirem maior liberdade temática aos periódicos jornalísticos, o que se verifica é uma sintonia entre o ritmo de publicações e a trajetória do processo no Poder Legislativo Federal. Esta situação é também identificada por Espinosa (2003), ao afirmar que os jornais não podem ignorar constrangimentos concernentes a eventos extraordinários em seus editoriais. Assim, o impeachment se mostra um assunto de grande interesse para a sociedade e, consequentemente, para as publicações.

A segunda hipótese dava conta que, de forma geral, os dois periódicos apresentam pontos de vista semelhantes em relação ao impeachment. Considera-se que ela também foi comprovada, uma vez que o "Argumento Legitimador" predominante nos dois periódicos é o mesmo, a saber, a "crise econômica". Tal constatação acaba por refutar a hipótese 3 . Ou seja, as duas publicações sustentam a legitimidade do afastamento de Dilma utilizando-se de argumentos ligados à seara econômica, e não em argumentos jurídicos. Aliás, argumentos jurídicos são apenas o segundo apelo mais frequente nos dois jornais; em OESP, enfatiza-se "crime de responsabilidade", enquanto na FSP destaca "normas legais". Por mais que os resultados apontem que os jornais se preocupem em dizer que o processo, formalmente, tem respaldo constitucional, - a Folha argumenta que o impeachment está previsto na Constituição e, portanto, seria um expediente legítimo -, a baixa menção a "crime de responsabilidade" corrobora a dúvida, pelo menos por parte da FSP, de que as pedaladas fiscais seriam suficientes para sustentar o afastamento da Presidente. Em suma, o fato de os jornais acionarem os "Argumentos Legitimadores" em proporções semelhantes (cerca de $85 \%$ ), mas, concomitantemente, empregando justificativas diversas ("crime de responsabilidade" é a segunda categoria mais recorrente em OESP e a última no caso da FSP), aponta posturas distintas dos dois periódicos. É curioso notar, contudo, que "crise econômica" foi o Argumento Legitimador mais utilizado nos editoriais de ambas as publicações, também denotando que o crime de responsabilidade a justificar a abertura do processo - e que era a acusação efetivamente dirigida à Presidente - ficou em segundo plano. É importante frisar, ademais, que OESP traduz uma preocupação clara com a esfera econômica (que se constitui como uma das diretrizes editoriais do periódico), tanto que boa parte das categorias mais recorrentes no periódico tem a ver com a questão. A ideia parece ser a de que o impeachment se mostraria 
desejável à medida que poderia acarretar melhora na situação econômica - aqui, uma vez mais, deixa-se de lado a consideração acerca das pedaladas fiscais como sustentação do afastamento de Dilma, contrariando o que é possível verificar a partir da postura da FSP.

Os dados permitem afirmar que os dois jornais, ainda que em graus distintos, deslocam o centro da discussão do campo político ou jurídico para o campo econômico. As regras do jogo democráticoconstitucional são mobilizadas de forma a garantir que o impeachment estaria a transcorrer de forma procedimentalmente correta. No entanto, parte dos argumentos legitimadores acionados, conforme indicado, diz respeito a fatores externos à esfera política, ainda que se trate de um processo essencialmente político. Ao conferir importância singular ao argumento de ordem econômica para sustentar o afastamento da presidente, os jornais acabam por legitimar a importância dos interesses econômicos no que tange ao encaminhamento de impasses que, em princípio, seriam típicos do campo político.

No mesmo sentido, chama atenção o fato de OESP utilizar, com alguma recorrência, a "voz do povo" como um Argumento Legitimador para o impeachment. Isso porque, em certos momentos (é o caso das manifestações de 2013, analisada por Mont'Alverne (2017)), os editoriais expressam descontentamento com a participação da população para além do momento eleitoral. 0 jornal chega a dizer, na oportunidade examinada pela autora citada logo acima, que o Parlamento seria a esfera adequada para manifestação de interesses divergentes, expressando limites sobre o quanto a interferência popular seria aceitável na política institucional de regimes democráticos. Já no período discutido no presente trabalho, a rejeição a Dilma e o apoio da população ao impeachment, registrados em sondagens de opinião, são apresentados como mais um fator de legitimação do processo.

Na realidade, "crise econômica" e "voz do povo", junto à menção a "crime de responsabilidade", a "normas legais" e a "corrupção e fisiologismo", são apresentadas como uma espécie de "conjunto da obra" para justificar a defesa do impeachment de Dilma por parte de OESP. O periódico, assim, não se limita a elencar apenas as razões que sustentam o pedido formal de afastamento da Presidente como Argumento Legitimador.

A FSP, por sua vez pouco arrola o "crime de responsabilidade" como justificativa. O caráter político do julgamento fica evidente, portanto, também nos editoriais que mobilizam argumentos a exemplo do mau desempenho econômico do país ou das baixas taxas de aprovação popular da então Presidente.

Os dois jornais também apresentam discordâncias em relação à melhor saída para a crise política. Se o posicionamento de OESP é favorável ao impeachment, a FSP prioriza, proporcionalmente, a ideia de renúncia de Dilma e Temer, seguida por novas eleições. Tal movimentação é justificada, em certos momentos, pela compreensão de que o impeachment, na visão do jornal, não seria solução para a crise, sobretudo porque Temer assumiria o cargo enfraquecido.

A FSP hesita, portanto, em aderir ao impedimento de Dilma como solução, embora defenda que afastamento da então presidente - mediante renúncia motivada por vontade própria, ao reconhecer que não haveria mais condições para se manter na Presidência -, seguido por novas eleições presidenciais, evitaria o "trauma" do impeachment.

A fim de abrir espaço para a proposição de investigações complementares acerca do caso aqui abordado, pede-se licença para refletir acerca de duas questões sugeridas pela análise empreendida, mas que devem permanecer somente no plano especulativo, uma vez que os dados não permitem comprovar os apontamentos a seguir. 
Em primeiro lugar, o pico de publicação de editoriais que tratam do impeachment tanto na FSP quanto em OESP talvez se dê em abril não somente porque este foi o mês de votação do relatório da Comissão na Câmara dos Deputados, mas, também, porque as duas publicações considerem que a aprovação do afastamento de Dilma naquele momento praticamente selaria o destino da então mandatária, fazendo com que o ânimo em tratar do assunto arrefecesse nos meses seguintes - inclusive houve menor quantidade de editoriais tratando do assunto no próprio mês em que o afastamento definitivo foi votado no Senado, em Agosto de 2016. Outra possibilidade para a maior frequência de textos publicados em Abril pode ser a tentativa, por parte das duas empresas jornalísticas, de atuarem como players do jogo político dispostas a convencer os parlamentares a cassarem o mandato de Dilma Rousseff. Assim, uma vez que o impeachment estaria "encaminhado" depois da votação na Câmara, o ânimo para continuar insistindo no tema teria diminuído. Ao mesmo tempo, é bom ressaltar, o assunto permanece em pauta e a sustentação de sua legitimidade junto ao público continua crucial até a aprovação do afastamento definitivo da ex-presidente pelo Senado, situação evidenciada pelo fato de o mês de Agosto de 2016 apresentar a maior concentração de ocorrências do Argumento Legitimador.

Em segundo lugar, mostra-se legítimo o seguinte questionamento: em que medida o fato de na variável "Saídas para a crise política" os jornais não terem certeza sobre a viabilidade do impeachment (especialmente, em Dezembro de 2015) faz com que FSP e OESP evitem apresentar uma solução direta? Conforme dito anteriormente, apenas $28 \%$ dos editoriais de FSP e OESP mencionam algum tipo de "Saída". Além disso, por qual motivo a FSP aponta poucas consequências do impeachment? Em alguns editoriais, a publicação defende que o afastamento de Dilma não seria suficiente para aplacar as crises. Ademais, a FSP também não apresenta "melhora da crise política" como consequência em seus editoriais examinados nos meses do estudo qualitativo. Será possível afirmar que a FSP temia uma instabilidade ainda maior pósimpeachment e, por isso, prefere sugerir que a renúncia da chapa Dilma-Temer seja seguida de novas eleições?

As observações apresentadas compõem a agenda de pesquisa a ser perseguida na sequência deste artigo. As descobertas aqui apontadas, bem como as especulações oferecidas logo acima, permitem a elaboração de novas hipóteses de trabalho que ajudam a investigar o posicionamento político dos jornais brasileiros a partir dos editoriais publicados diariamente.

\section{Considerações finais}

O objetivo do artigo foi examinar de que forma os jornais Folha de S. Paulo e O Estado de S. Paulo abordaram, em seus editoriais, o processo de impeachment da ex-presidente Dilma Rousseff. Os dados apresentados e discutidos anteriormente permitem afirmar que FSP e OESP assumem, em momentos distintos do desenvolvimento do processo, a defesa de que o impeachment deveria acontecer. Isso vem acompanhado de uma tentativa persistente, por parte das duas publicações, em justificar, com base em argumentos peculiares, a legitimidade do afastamento - a intenção de fundo das referidas publicações é argumentar que estariam respeitando as regras da democracia, construindo uma imagem positiva de si. Os dados comprovam que os dois periódicos priorizam a apresentação de "Argumentos Legitimadores", mas as ênfases sobre quais apelos são os mais legítimos têm naturezas distintas, a depender da publicação. 
Merece ser observada, portanto, uma questão de construção de imagem - e de preservação de credibilidade - por parte dos periódicos. Eles tomam como ponto de partida a ideia de que uma ruptura constitucional não é recomendável. Assim, precisariam provar para a sociedade a necessidade e a legalidade do afastamento da Presidente - o que significa disputar, com outros atores políticos e sociais, o enquadramento sobre tratar-se ou não de um "golpe".

Neste sentido, o editorial é percebido não somente como uma forma que o Jornalismo encontra para manter agentes e instituições do campo político accountable à medida que são examinados os meios e os modos pelos quais a legitimidade do processo de impeachment é construída, a própria empresa também se preocupa em prestar contas - é o caso da Folha de S. Paulo, quando publica editoriais na capa (o que aconteceu duas vezes durante o período analisado). Os editoriais são utilizados, ainda, como forma de colocar o impeachment em pauta, ao tratarem da temática desde o início do segundo mandato de Dilma. Isto não redunda, porém, em uma adesão sem restrições ao afastamento da Presidente. Os jornais acreditam que o caminho para a recuperação econômica e para a resolução do impasse político passa pela saída de Dilma do cargo, mas discordam quanto à maneira pela qual isto deve acontecer. Também não há consenso sobre se Michel Temer na Presidência seria uma opção adequada para resolver os problemas do país.

O que fica clara é a utilização, por parte dos jornais, de sua opinião institucional (em um dos mais nobres espaços de ambos os periódicos) com o intuito de construir a legitimidade acerca da deposição de Dilma Rousseff - tanto que, quando o assunto parece estar definido, logo após a votação sobre o impeachment no Plenário da Câmara dos Deputados em abril de 2016, a atenção dispensada ao afastamento da então mandatária diminui consideravelmente. Assim, por um lado, FSP e OESP se mostram incisivamente preocupados em justificar por que a então Presidente deveria ser retirada do gabinete. Por outro lado, contudo, os periódicos não se dedicam, com a mesma ênfase, a especular sobre quais seriam as consequências do processo em questão; menos, ainda, dão atenção às possíveis soluções para o impasse político, o que implica, de certa maneira, a falha de tais textos opinativos em orientar o leitor (Alves Filho 2006; Beltrão 1980; Melo 1985).

No caso em tela, também ficam evidentes os limites do editorial como diferenciador mercadológico e ideológico das duas publicações. Em outras palavras, ainda que existam diferenças entre os posicionamentos apresentados, os jornais defendem, essencialmente, a mesma coisa, apontando para determinada confluência em seus interesses (Albuquerque 2017).

Em resumo, FSP e OESP convergem quanto à necessidade de afastar Dilma Rousseff, mas não entram em acordo sobre os métodos pelos quais isso deveria acontecer ou sobre quem estaria em condições de substituí-la. É possível afirmar, portanto, que dois dos mais importantes jornais do país, ao defenderem a saída da então Presidente do cargo, lançaram mão de seus editoriais a fim de atuarem como agentes políticos.

\section{Referências}

Albuquerque, Afonso De. 2017. "Protecting Democracy or Conspiring against It? Media and Politics in Latin America: A Glimpse from Brazil." Journalism: 1-18. 
Alves Filho, Francisco. 2006. "A Autoria Institucional Nos Editoriais De Jornais." Alfa 50(1): 77-89.

Armañanzas, Emy., and Javier Díaz Nocí. 1996. Periodismo y Argumentación. Géneros de Opinión. Universidad del País Vasco.

Azevedo, F. A. 2005. "Imprensa e Legislativo: Os Editoriais Da Folha de S. Paulo Sobre o Senado (20032004)." http://www.compos.org.br/data/biblioteca_793.pdf.

Azevedo, F. A., and V. L. M. Chaia. 2008. "O Senado Nos Editoriais Dos Jornais Paulistas (2003-2004)." Opinião Pública 14(1): 173-204. http://www.scielo.br/scielo.php?pid=S010462762008000100007\&script=sci_arttext\&tIng=pt.

Azevedo, Fernando. 2016. "A Grande Imprensa Brasileira: Paralelismo Político e Antipetismo (1989-2014)." Universidade Federal de São Carlos.

Bardin, Laurence. 1977. Análise de Conteúdo. Lisboa: Edições 70.

Barros Filho, C. 1995. Ética Na Comunicação: De Informação Ao Receptor. São Paulo: Moderna.

Bauer, Martin W. 2002. "Análise de Conteúdo Clássica: Uma Revisão." In Pesquisa Qualitativa Com Texto, Imagem e Som: Um Manual Prático., eds. Martin W Bauer and George. Gaskell. Rio de Janeiro: Vozes, 189-217.

Beltrão, Luiz. 1980. Jornalismo Opinativo. Porto Alegre: Sulina.

Bennett, W. L. 1988. News: The Politics of Illusion. New York: Longman.

Billeaudeaux, Andre, David Domke, John S Hutcheson, and Philip Garland. 2003. "Newspaper Editorials Follow Lead of Bush Administration." Newspaper Research Journal 24(1): 166-84.

Breed, Warren. 1955. "Newspaper 'Opinion Leaders' and Processes of Standardization." Journalism Quarterly 35(3): 277-84.

Bucci, Eugenio. 2000. Sobre Ética e Imprensa. São Paulo: Companhia das Letras.

Campos, Luiz Augusto. 2014. "A Identificacao de Enquadramentos Através Da Análise de Correspondências: Um Modelo Analítico Aplicado à Controvérsia Das Ações Afirmativas Raciais Na Imprensa." Opinião Pública 20(3): 377-406.

Capelato, Maria Helena., and Maria Lígia. Prado. 1980. O Bravo Matutino: Imprensa e Ideologia No Jornal O Estado de S. Paulo. São Paulo: Alfa-Ômega.

Cavalcante, Ricardo Bezerra., Pedro. Calixto, and Marta Macedo Kerr. Pinheiro. 2014. "Análise de Conteúdo: Considerações Gerais, Relações Com a Pergunta de Pesquisa, Possibilidades e Limitações Do Método." Informação \& Sociedade: Estudos 24(1): 13-18.

Chaparro, Manuel Carlos. 2003. "Jornalismo Não Se Divide Em Opinião e Informação." http://tinyurl.com/ak362mk.

Chiang, Chun Fang., and Brian. Knight. 2008. "Media Bias and Influence: Evidence from Newspaper Endorsements ." https://ideas.repec.org/p/nbr/nberwo/14445.html.

Clark, Anna. 2014. "Why Some Newspapers Are Abandoning Endorsements ." http://www.cjr.org/united_states_project/why_some_newspapers_are_abandoning_endorsement s.php.

Clayman, S. E. 2002. "Tribune of the People: Maintaining the Legitimacy of Aggressive Journalism." Media, $\begin{array}{llll}\text { Culture } \quad \& \quad \text { Society } & \text { 24(2): }\end{array}$ http://mcs.sagepub.com/cgi/doi/10.1177/016344370202400203.

Clayman, S. E., Marc N. Elliott, John Heritage, and Laurie L. McDonald. 2006. "Historical Trends in 
Questioning Presidents, 1953-2000." Presidential Studies Quarterly 36(4): 561-83.

Clayman, S. E., J. Heritage, M. N. Elliott, and L. L. McDonald. 2007. "When Does the Watchdog Bark? Conditions of Aggressive Questioning in Presidential News Conferences." American Sociological Review 72(2005): 23-41.

Costa, Izabel Cristina Gomes. 2009. "Quem Fará a Nossa Perestroika? Imagens de Mikhail Gorbatchev No Jornal O Globo." Tempo 13(25): 139-64. http://www.scopus.com/inward/record.url?eid=2-s2.067649763972\&partnerID=tZOtx3y1.

Van Dalen, Arjen. 2012. "Structural Bias in Cross-National Perspective: How Political Systems and Journalism Cultures Influence Government Dominance in the News." The International Journal of Press/Politics 17(1): 32-55. http://hij.sagepub.com/cgi/doi/10.1177/1940161211411087.

Dias, André Bonsanto. 2012. "O PRESENTE DA MEMÓRIA. Usos Do Passado e as ( Re ) Construções de Identidade Da Folha de S. Paulo , Entre o 'golpe de 1964' e a 'Ditabranda."' Universidade Federal do Paraná.

Druckman, James N., and Michael Parkin. 2005. "The Impact of Media Bias: How Editorial Slant Affects Voters." The Journal of Politics 67(4): 1030-49.

Eilders, C. 1999. "Synchronization of Issue Agendas in News and Editorials of the Prestige Press in Germany." The International Journal of Communications Research 24(3): 301-28.

Eriksson, G., and J. Ostman. 2013. "Cooperative or Adversarial? Journalists' Enactment of the Watchdog Function in Political News Production." The International Journal of Press/Politics 18(3): 304-24. http://hij.sagepub.com/cgi/doi/10.1177/1940161213482493.

Espinosa, Pastora Moreno. 2003. "Géneros Para La Persuasión En Prensa: Los Editoriales Del Diario El País." Ámbitos (10): 225-38.

Gieber, Walter. 1956. "Across the Desk: A Study of 16 Telegraph Editors." Journalism Quaterly 33(4): 42332.

Giobbe, Dorothy. 1994. "Boycott over Editorial Ends Happily for Thrice-Weekly S.C. Paper." Editor \& Publisher: 19.

Guerreiro Neto, Guilherme. 2016. "Da Opinião à Identidade: Características Do Editorial Em Dois Jornais Brasileiros." Sobre Jornalismo 5(2): 92-105.

Hallin, Daniel C., and Paolo Mancini. 2004. Comparing Media Systems: Three Models of Media and Politics. Cambridge: Cambridge University Press. http://www.loc.gov/catdir/samples/cam041/2003069684.html.

Izadi, Foad, and Hakimeh Saghaye-Biria. 2007. "A Discourse Analysis of Elite American Newspaper Editorials: The Case of Iran's Nuclear Program." Journal of Communication Inquiry 31(2): 140-65.

Kahn, Kim Fridkin, and Patrick J Kenney. 2002. "The Slant of the News: How Editorial Endorsements Influence Campaign Coverage and Citizens Views of Candidates." American Political Science Review 96(2): 381-94.

Krippendorff, Klaus. 2004. Content Analysis: An Introduction to Its Methodology. London: Sage Publications. Lacy, Stephen, Brendan R. Watson, Daniel Riffe, and Jennette Lovejoy. 2015. "Issues and Best Practices in Content Analysis." Journalism \& Mass Communication Quarterly 92(4): 791-811. http://journals.sagepub.com/doi/10.1177/1077699015607338.

Lasch, C. 1995. "Journalism, Publicity, and the Lost Art of Argument." Media Studies Journal 9(1): 81-91. 
Lattman-Weltman, Fernando. 2003. "Folha de S. Paulo: Ambiguidade e Inovação." In Eles Mudaram a Imprensa: Depoimentos Ao CPDOC, eds. A. Abreu, Fernando Lattman-Weltman, and D. Rocha. Rio de Janeiro: Editora FGV, 345-50.

Marques, Francisco Paulo Jamil Almeida, Edna Miola, and Nayana Siebra. 2014. "Jornalismo, Assessoria De Imprensa E Seus Condicionantes Organizacionais: Uma Reflexão a Partir Das Teorias Do Jornalismo." Animus 13(25): 145-66.

McCombs, Maxwell. 2005. "A Look at Agenda-Setting: Past, Present and Future." Journalism Studies 6(4): 543-57.

McCombs, Maxwell, and Donald Shaw. 1972. "The Agenda- Setting Function of Mass Media." Public Opinion Quarterly 36(2): 176-87.

Melo, José Marques de. 1985. A Opinião No Jornalismo Brasileiro. Petrópolis NV - 166: Vozes.

Meltzer, K. 2007. "Newspaper Editorial Boards and the Practice of Endorsing Candidates for Political Office in the United States." http://jou.sagepub.com/cgi/doi/10.1177/1464884907072422.

Miguel, Luis Felipe, and Aline De Almeida Coutinho. 2007. "A Crise e Suas Fronteiras: Oito Meses de 'Mensalão' Nos Editoriais Dos Jornais." Opinião Pública 13(1): 97-123. http://www.scielo.br/scielo.php?script=sci_arttext\&pid=S0104$62762007000100004 \&$ Ing =pt\&nrm=iso\&tlng=pt.

Mont'Alverne, Camila. 2017. "'Rebeldia e Desalento': Um Estudo Sobre o Agendamento Do Congresso Nacional Brasileiro Nos Editoriais Da Folha de S. Paulo e de O Estado de S. Paulo." Revista Compolítica 7(2): 271-98.

Mont'Alverne, Camila, and Francisco Paulo Jamil Marques. 2016. "A PAUTA DO DIA: Um Estudo Sobre o Agendamento Do Congresso Nacional Brasileiro Nos Editoriais Da Folha de S. Paulo e de O Estado de S. Paulo." Brazilian Journalism Research 12(2): 120-47.

Mont'Alverne, Camila, and Francisco Paulo Jamil Almeida Marques. 2013. "JORNALISMO POLÍTICO E IMAGEM PÚBLICA Dilma Rousseff Nos Editoriais Do Jornal O Estado de S. Paulo." Contracampo: 27.

Moraes, Cláudia Herte de. 2007. "Parcialidade Alardeada: Notas Sobre a ImportâNcia Da Opinião No Jornalismo." Anais do XI Colóquio da Celacom: 9. http://encipecom.metodista.br/mediawiki/index.php/Parcialidade_alardeada:_notas_sobre_a_imp ortância_da_opinião_no_jornalismo.

Nunes Neto, Carmen Aparecida. 2012. "O Mercosul Na Visão Retórico-Discursiva Dos Editoriais Dos Jornais Gazeta Do Iguaçu (BR) e Vanguardia (PY)." Universidade Estadual do Oeste do Paraná.

Pereira, Idílio Medina. 2011. "Debate Público e Opinião Da Imprensa Sobre a Política de Cotas Raciais Na Universidade Pública Brasileira." Universidade Federal do Rio Grande do Sul.

Pilagallo, O. 2012. História Da Imprensa Paulista: Jornalismo e Poder de D. Pedro I a Dilma. São Paulo: Três Estrelas.

Pratte, Alf, and Gordon Whiting. 1986. "What Newspaper Editorials Have Said about Deregulation of Broadcasting." Journalism Quarterly 697-502. https://doi.org/10.1177/107769908606300307.

Ramonet, I. 1999. A Tirania Da Comunicação. Petrópolis: Vozes. 
Ribeiro, Ana Paula Goulart. 2003. "Jornalismo, Literatura e Política: A Modernização Da Imprensa Carioca Nos Anos 1950." Estudos Históricos 31: 147-60.

Scarrow, H. A., and Steve Borman. 1979. "The Effects of Newspaper Endorsements on Election Outcomes: A Case Study." The Public Opinion Quarterly 43(3): 388-93.

Shaw, Eugene F. 1979. "Agenda-Setting and Mass Communication Theory." International Communication Gazette 36: 176-87.

Shehata, Adam, and Jesper Strömbäck. 2013. "Not (Yet) a New Era of Minimal Effects: A Study of Agenda Setting at the Aggregate and Individual Levels." The International Journal of Press/Politics 18(2): 234-55. https://doi.org/10.1177/1940161212473831.

Sigelman, Lee. 1973. "Reporting the News: An Organizational Analysis." American Journal of Sociology 79(1): 132-51.

Sodré, Nelson Werneck. 1999. História Da Imprensa No Brasil. Rio de Janeiro: Mauad.

Soloski, John. 1999. "O Jornalismo e o Profissionalismo: Alguns Constrangimentos No Trabalho Jornalístico." In Jornalismo: Questões, Teorias e "Estórias," ed. Nelson. Traquina. Lisboa: Vega, 91-100.

Staff, Editor \& Publisher. 2007. "Readers Respond to California Paper's 'How Many More?' Editorial on Iraq Dead." Editor \& Publisher.

Tang, Zhilin. 2011. "Burgeoning Democracy or Threatening Security? The Ambiguous Voice of the American Press on Taiwan's Independence." Critical Sociology 37(6): 837-52.

Traquina, Nelson. 2005. 1 Teorias Do Jornalismo - Por Que as Notícias São Como São. Florianópolis: Insular. Weaver, David H. 2015. "Agenda-Setting." In The International Encyclopedia of Political Communication, ed. Gianpietro Mazzoleni. John Wiley \& Sons, 1-9. http://doi.wiley.com/10.1002/9781118541555.wbiepc016. 